Article

\title{
Determination and Data Correlation of Solubility of Sofosbuvir Polymorphs in Ethyl Acetate + Toluene and Methyl tert-Butyl Ether Binary Solvents at the Temperature Range from 268.15 to $308.15 \mathrm{~K}$
}

\author{
Wei-Jie Ji, En-Fu Wang and Ming-Hui Qi *D \\ Engineering Research Centre of Pharmaceutical Process Chemistry, Ministry of Education; Laboratory of \\ Pharmaceutical Crystal Engineering \& Technology, School of Pharmacy, East China University of Science and \\ Technology, Shanghai 200237, China; jiweijieecust@sina.com (W.-J.J.); Y45140254@mail.ecust.edu.cn (E.-F.W.) \\ * Correspondence: mhqi@ecust.edu.cn
}

Received: 27 December 2019; Accepted: 13 March 2020; Published: 17 March 2020

check for updates

\begin{abstract}
A gravimetric method was used to experimentally determine the (solid + liquid) equilibrium of sofosbuvir of crystalline forms A and B in both ethyl acetate + toluene and methyl tert-butyl ether $(\mathrm{MTBE})+$ toluene binary solvents systems at atmosphere pressure. Experiments were carried out at a temperature range of 268.15-308.15 K. Results show that the solubility of sofosbuvir increases with temperature, and the solubility of form B was higher than that of form A. The modified Apelblat model, the CNIBS/Redlich-Kister model, and the combined version of Jouyban-Acree model were employed to correlate the measured solubility data, respectively. Furthermore, an examination of the solid-state stability of the two polymorphs was conducted, finding that form A and form B exhibit good solid-state stability under high temperature, high humidity, and strong light exposure conditions.
\end{abstract}

Keywords: sofosbuvir; polymorph; solubility; binary solvents; data correlation

\section{Introduction}

Sofosbuvir $\left(\mathrm{C}_{22} \mathrm{H}_{29} \mathrm{FN}_{3} \mathrm{O}_{9} \mathrm{P}\right.$, CAS No.: 1190307-88-0, presented in Figure 1) is a novel anti-HCV agent, offering a more satisfactory sustained virologic response rate than those that have ever been used in similar cases before [1,2]. It is indicated by our previous studies that ethyl acetate + toluene and $\mathrm{MTBE}+$ toluene binary systems can be used to crystallize sofosbuvir of form A or B [3]. However, there is no literature that has reported the solution thermodynamic data of sofosbuvir in these two systems. These are important for the optimization of the crystallization process, especially for the controlling of polymorphs, since the various solid forms generally present different physicochemical properties.

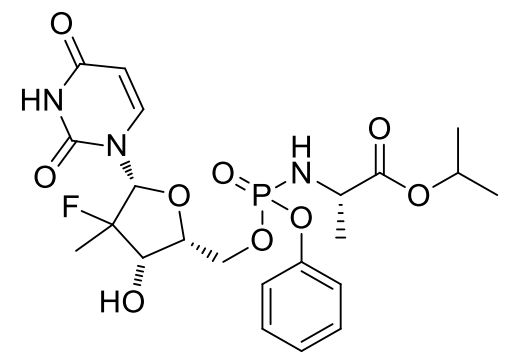

Figure 1. Chemical structure of sofosbuvir.

In this study, a gravimetric method [4-6] was used to acquire the solubility data of sofosbuvir of forms A and B in both ethyl acetate + toluene binary solvents with ethyl acetate mole fraction 
ranging from 0.32 to 0.53 , and MTBE + toluene binary solvents with MTBE mole fraction ranging from 0.40 to 0.77 , at atmosphere pressure, with a temperature range of $268.15-308.15 \mathrm{~K}$. The experimental data were correlated using the modified Apelblat model, the CNIBS (combined nearly ideal binary solvent)/Redlich-Kister model, and the combined version of Jouyban-Acree model. A stability test according to International Conference for Harmonization Quality Guidelines was conducted as well, to disclose the solid-state stability of sofosbuvir polymorphs under the influence of a variety of environmental factors such as temperature, humidity, and light. This can provide experimental data for establishing a re-test period for active pharmaceutical ingredients or a shelf life for the drug product and recommended storage conditions.

\section{Modeling}

Correlation of the experimental solubility data with different models is helpful for further understanding the thermodynamic properties in the measurement range. With this consideration, three models were used in this study. The modified Apelblat equation describes the dependence of solubility on temperature, the CNIBS/ Redlich-Kister model describes the dependence of solubility on solvent composition, while the Jouyban-Acree model describes the dependence of solubility on both parameters.

\subsection{Modified Apelblat Equation}

The Apelblat equation, as a well-known equation used to correlate solubility, was originally proposed by Apelblat and Manzurola; in it, the temperature dependence of the mole fraction solubility in different solvents is described as follows [7-11]:

$$
\ln x_{A}=A+\frac{B}{T}+C \ln T
$$

where $x_{A}$ is the mole fraction solubility and $T$ represents the corresponding absolute temperature. $A, B$ and $C$ are semi-empirical parameters of the model.

\subsection{CNIBS/Redlich-Kister Model}

The governing equation of CNIBS/Redlich-Kister model $[12,13]$ is defined as follows:

$$
\ln x_{A}=x_{B}^{0} \ln \left(x_{A}\right)_{B}+x_{C}^{0} \ln \left(x_{A}\right)_{C}+x_{B}^{0} x_{C}^{0} \sum_{i=0}^{N} S_{i}\left(x_{B}^{0}-x_{C}^{0}\right)^{i}
$$

where $x_{B}{ }^{0}$ and $x_{C}{ }^{0}$ are the mole fraction of each solvent in a binary solvent system, respectively; $N$ is the number of "curve-fit" parameters and $S_{i}$ is the model constant, which is two for a binary solvent system in this case; thus, $x_{C}{ }^{0}$ can be represented as $\left(1-x_{B}{ }^{0}\right)$. Substituting $x_{C}{ }^{0}$, Equation (2) can be expressed as:

$$
\begin{aligned}
& \ln x_{A}=\left(\ln \left(x_{A}\right)_{B}-\ln \left(x_{A}\right)_{C}+S_{0}-S_{1}+S_{2}\right) x_{B}^{0} \\
& +\left(-S_{0}+3 S_{1}-5 S_{2}\right)\left(x_{B}^{0}\right)^{2}+\left(-2 S_{1}+8 S_{2}\right)\left(x_{B}^{0}\right)^{3} \\
& +\left(-4 S_{2}\right)\left(x_{B}^{0}\right)^{4}+\ln \left(x_{A}\right)_{C}
\end{aligned}
$$

Changing constants in Equation (3) with a constant term $A_{i}\left(A_{0}, A_{1}, A_{2}, A_{3}, A_{4}\right)$, the CNIBS/R-K model can be simplified as follows [14,15]:

$$
\ln x_{A}=A_{0}+A_{1} x_{B}^{0}+A_{2}\left(x_{B}^{0}\right)^{2}+A_{3}\left(x_{B}^{0}\right)^{3}+A_{4}\left(x_{B}^{0}\right)^{4}
$$




\subsection{Jouyban-Acree Model}

The original function of Jouyban-Acree model, which was obtained by modifying the CNIBS/R-K model, is shown below [16]:

$$
\ln x_{A}=x_{B}^{0} \ln \left(x_{A}\right)_{B}+x_{C}^{0} \ln \left(x_{A}\right)_{C}+x_{B}^{0} x_{C}^{0} \sum_{i=0}^{N} \frac{J_{i}}{T}\left(x_{B}^{0}-x_{C}^{0}\right)^{i}
$$

in which $J_{i}$ is a constant of the function.

In order to enlarge the applicability of solution behavior of non-ideal systems, the modified Apelblat equation can be used to substitute $\ln \left(x_{A}\right)_{i}$; then Equation (6) is obtained, as in the CNIBS/R-K model:

$$
\begin{aligned}
& \ln x_{A}=a_{B}+\frac{b_{B}}{T}+c_{C} \ln T+\left(a_{B}-a_{C}\right) x_{B}^{0}+\left(b_{1}-b_{2}+J_{0}-J_{1}+J_{2}\right) \frac{x_{B}^{0}}{T} \\
& +\left(3 J_{1}-J_{0}-5 J_{2}\right) \frac{\left(x_{B}^{0}\right)^{2}}{T}+\left(8 J_{2}-2 J_{1}\right) \frac{\left(x_{B}^{0}\right)^{3}}{T} \\
& +\left(-4 J_{2}\right) \frac{\left(x_{B}^{0}\right)^{4}}{T}+\left(c_{B}-c_{C}\right) x_{B}^{0} \ln T
\end{aligned}
$$

A final equation of the Jouyban-Acree model can be obtained by simplifying equation 6 as well, with a constant term $B_{i}$ (containing $B_{0}, B_{1}, B_{2}, B_{3}, B_{4}, B_{5}, B_{6}, B_{7}, B_{8}$ ) [17]:

$$
\begin{aligned}
& \ln x_{A}=B_{0}+\frac{B_{1}}{T}+B_{2} \ln T+B_{3} x_{B}^{0}+B_{4} \frac{x_{B}^{0}}{T}+B_{5} \frac{\left(x_{B}^{0}\right)^{2}}{T}+B_{6} \frac{\left(x_{B}^{0}\right)^{3}}{T} \\
& +B_{7} \frac{\left(x_{B}^{0}\right)^{4}}{T}+B_{8} x_{B}^{0} \ln T
\end{aligned}
$$

\section{Experimental Section}

\subsection{Materials.}

Sofosbuvir of forms $\mathbf{A}$ and $\mathbf{B}$ was prepared and identified using the methods published in previous studies [3]. Ethyl acetate, MTBE and toluene were of analytical grade and used without further purification. Detailed information on the above-mentioned materials is listed in Table 1.

Table 1. Sources and purity of the materials.

\begin{tabular}{ccccc}
\hline Chemical Name & Source & $\begin{array}{c}\text { Purification } \\
\text { Method }\end{array}$ & $\begin{array}{c}\text { Mass Fraction } \\
\text { Purity }\end{array}$ & Analysis Method \\
\hline Sofosbuvir (form A) & synthesis & crystallization & $>0.99$ & HPLC $^{\text {a }}$ \\
Sofosbuvir (form B) & synthesis & crystallization & $>0.99$ & HPLC \\
Ethyl acetate & Sinopharm & none & 0.995 & GC ${ }^{\text {b }}$ \\
Toluene & Sinopharm & none & 0.995 & GC \\
MTBE & Sinopharm & none & 0.995 & GC \\
\hline \multicolumn{4}{c}{}
\end{tabular}

\subsection{Characterization of Sofosbuvir Polymorphs}

Powder X-ray diffraction (PXRD) was used to identify the crystalline form of sofosbuvir, and the patterns were recorded using a Rigaku Ultima IV diffractometer with $\mathrm{Cu} \mathrm{K} \alpha$ radiation $(40 \mathrm{kV}, 40 \mathrm{~mA})$ scanned at $20^{\circ} / \mathrm{min}$ over an angular range of $5-45^{\circ}$ of $2 \theta$. The patterns are shown in Figure 2 , and the main PXRD data are listed in Table S1, Supplementary Information. 


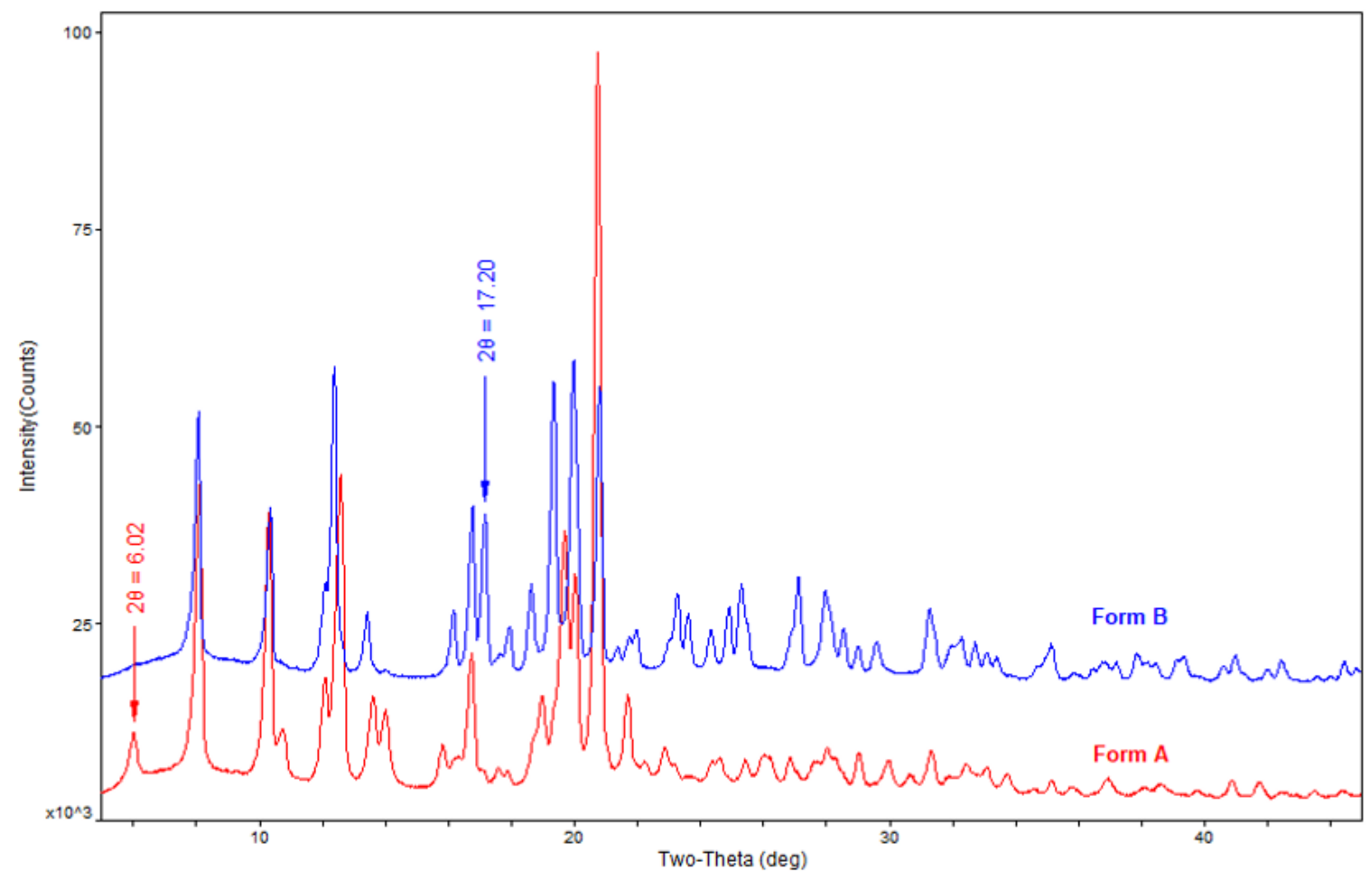

Figure 2. Powder X-ray diffraction (PXRD) patterns of sofosbuvir of form A and form $\mathbf{B}$.

\subsection{Stability Test}

\subsubsection{Temperature}

The two polymorphs of sofosbuvir were kept for 10 days at a temperature of $60 \pm 2{ }^{\circ} \mathrm{C}$ and sampled on the 5th and 10th day, respectively. PXRD analysis shows no obvious changes, which means that the solid-state stability of the two polymorphs is good at high temperature conditions. The patterns are given in Figures S1 and S2, Supplementary Information.

\subsubsection{Humidity}

The two polymorphs of sofosbuvir were kept for 10 days at a humidity of $\mathrm{RH} 92.5 \pm 5 \%$ and sampled on the 5th and 10th day, respectively. PXRD analysis shows no obvious changes, which means that the solid-state stability of the two polymorphs is good at high humidity conditions. The patterns are given in Figures S3 and S4, Supplementary Information.

\subsubsection{Light}

The two polymorphs of sofosbuvir were kept for 10 days under a light illumination of $4500 \pm$ 500 lux and sampled on the 5th and 10th day, respectively. PXRD analysis shows no obvious changes, which means that the solid-state stability of the two polymorphs is good at strong light exposure conditions. The patterns are given in Figures S5 and S6, Supplementary Information.

\subsection{Solubility Measurement}

Sufficient amounts of sofosbuvir polymorphs were added to $25 \mathrm{ml}$ solvent in a $50 \mathrm{ml}$ jacket glass vessel with a magnetic stir bar and a thermometer, to form a saturated solution. A thermostatic bath was employed to control the temperature with an accuracy of $\pm 0.1 \mathrm{~K}$. The solution was agitated for $2 \mathrm{~h}$ to ensure that the system had reached the state of solid-liquid equilibrium. Then the stirring was stopped and the solution was kept stationary for $10 \mathrm{~min}$. Subsequently, the upper clear solution (about $5 \mathrm{~mL})$ was transferred into a small beaker using a membrane filter $(0.45 \mu \mathrm{m})$. The beaker was dried 
in a vacuum oven at $333.15 \mathrm{~K}$ for about $48 \mathrm{~h}$ to make sure that the weight of the beakers became constant. Both of the polymorphs were proved by PXRD to be maintained over the temperature range. Measurements were conducted in triplicate at each temperature to minimize the relative deviation. All of the masses were measured using an analytical balance (Mettler Toledo XS105, Switzerland) with an accuracy of $\pm 0.01 \mathrm{mg}$.

The solubility of the sofosbuvir polymorphs, described in mole fraction $x$ in different systems, was calculated by the following equation [18]:

$$
x=\frac{\frac{m}{M}}{\frac{m}{M}+\sum\left(\frac{m_{s}}{M_{s}}\right)}
$$

in which $m$ and $m_{S}$ represent the mass of sofosbuvir and the solvent, respectively; $M$ and $M_{S}$ are the molecular mass of sofosbuvir and the solvent, respectively.

\section{Results and Discussion}

\subsection{Solubility Data in Binary Solvents}

Experimental data on solubility measurement are presented in Tables S2-S5, Supplementary Information, and graphically illustrated in Figure 3; Figure 4. It is obvious that the solubility of sofosbuvir increases with the temperature and the mole fraction of ethyl acetate or MTBE. Solubility of form $\mathbf{B}$ is higher than that of form $\mathbf{A}$ under all of the experimental conditions, which means that form $\mathbf{A}$ is more stable than form $\mathbf{B}$ at the temperature range of measurement. The relative thermodynamic stability is in line with our previous research [3].

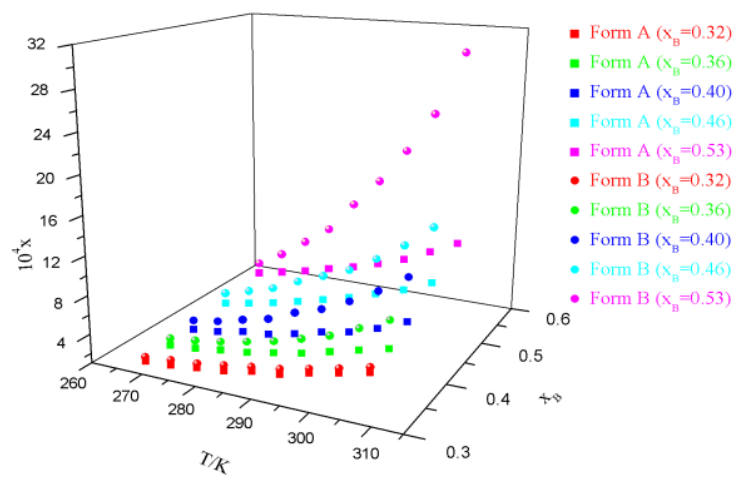

Figure 3. Experimental solubility $\left(x_{A}\right)$ of form A and form B in ethyl acetate + toluene binary solvents.

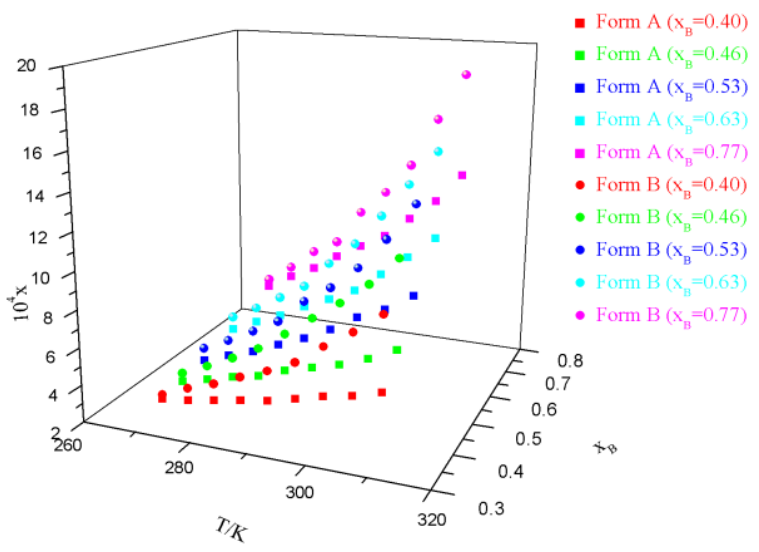

Figure 4. Experimental solubility $\left(x_{A}\right)$ of form A and form B in MTBE + toluene binary solvents. 


\subsection{Data Correlation}

The Apelblat model, the CNIBS/Redlich-Kister model, and the Jouyban-Acree model were used to correlate the solubility data, based on the average relative deviation ( $A R D)$ defined by Equation (9), which was used to compare among three different models [19].

$$
A R D \%=\frac{100}{N} \sum_{i=1}^{N}\left|\frac{x_{A, i}-x_{A, i}^{c a l}}{x_{A, i}}\right|
$$

in which $N$ is the number of the experimental measurement, $x_{A, i}$ is each measured solubility and $x_{A, i}{ }^{c a l}$ is each calculated value. The 1stOpt program was applied to calculate the data using Equations (1), (4), and (7).

Parameters of data correlation and values of $A R D \%$ for each individual modeling system are listed in Tables 2-7, with which the calculated solubility values were obtained and listed in Tables S2-S5, Supplementary Information. It was observed that experimental solubility data are satisfactory, fitting with the calculated solubility values. Values of $A R D \%$ calculated by the modified Apelblat model, the CNIBS/R-K model, and the Jouyban-Acree model are less than $2.41 \%, 0.88 \%$, and $4.06 \%$, respectively, indicating that the three models all correlate well in this system. After comparing calculated stabilities with corresponding experimental ones, the CNIBS/R-K model stood out to be more suitable with a higher accuracy than the other two models.

Table 2. Fitting parameters of modified Apelblat model for ethyl acetate + toluene system.

\begin{tabular}{rcccc}
\hline $\boldsymbol{x}_{\boldsymbol{B}}{ }^{\mathbf{0}}$ & $\boldsymbol{A}$ & $\boldsymbol{B}$ & $\boldsymbol{C}$ & $\boldsymbol{A R D \%}$ \\
\hline Form A & & & & \\
0.32 & -19.11 & -1655.76 & 4.55 & 2.13 \\
0.36 & 55.30 & -5021.69 & -6.51 & 1.58 \\
0.40 & -70.83 & 416.91 & 12.45 & 2.41 \\
0.46 & 70.70 & -5406.75 & -8.91 & 0.90 \\
0.53 & -101.85 & 2463.61 & 16.78 & 0.88 \\
Form B & & & & \\
0.32 & -118.97 & 3120.84 & 19.29 & 1.07 \\
0.36 & -187.47 & 5626.11 & 29.90 & 0.62 \\
0.40 & -73.51 & 508.07 & 12.96 & 1.10 \\
0.46 & -36.90 & -873.12 & 7.39 & 1.31 \\
0.53 & 30.75 & -4517.73 & -2.22 & 1.86 \\
\hline
\end{tabular}

Table 3. Fitting parameters of modified Apelblat model for MTBE + toluene system.

\begin{tabular}{rcccc}
\hline$x_{B}{ }^{0}$ & $A$ & $B$ & $C$ & $A R D \%$ \\
\hline Form A & & & & \\
0.40 & -48.64 & 794.58 & 8.30 & 0.55 \\
0.46 & 1.45 & -1661.09 & 1.00 & 1.24 \\
0.53 & 76.70 & -5256.26 & -10.05 & 0.73 \\
0.63 & -43.24 & -54.52 & 7.98 & 1.26 \\
0.77 & -47.35 & 302.27 & 8.53 & 1.43 \\
Form B & & & & \\
0.40 & -27.26 & -937.26 & 5.66 & 1.46 \\
0.46 & 97.35 & -6501.56 & -12.89 & 0.72 \\
0.53 & -60.70 & 323.62 & 10.85 & 1.08 \\
0.63 & 1.13 & -2362.87 & 1.61 & 1.18 \\
0.77 & -97.89 & 1952.94 & 16.48 & 1.65 \\
\hline
\end{tabular}


Table 4. Parameters of CNIBS/R-K model for ethyl acetate + toluene system.

\begin{tabular}{ccccccc}
\hline $\boldsymbol{T} / \mathbf{K}$ & $A_{\mathbf{0}}$ & $A_{\mathbf{1}}$ & $A_{\mathbf{2}}$ & $A_{\mathbf{3}}$ & $A_{\mathbf{4}}$ & $A R \boldsymbol{D}^{\%}$ \\
\hline Form A & & & & & & \\
268.15 & -44.17 & 469.34 & -1833.07 & 3119.79 & -1938.72 & 0.31 \\
273.15 & -19.22 & 221.48 & -922.75 & 1664.43 & -1082.88 & 0.42 \\
278.15 & -3.58 & 59.73 & -298.58 & 616.49 & -437.45 & 0.06 \\
283.15 & -64.11 & 669.20 & -2567.66 & 4325.46 & -2682.28 & 0.06 \\
288.15 & -38.48 & 415.32 & -1626.87 & 2795.33 & -1762.46 & 0.06 \\
293.15 & -21.05 & 226.97 & -879.77 & 1515.09 & -960.63 & 0.01 \\
298.15 & -66.28 & 682.86 & -2568.42 & 4252.38 & -2600.93 & 0.05 \\
303.15 & -42.04 & 436.51 & -1636.54 & 2708.64 & -1656.26 & $3.35 \times 10^{-3}$ \\
308.15 & 24.61 & -221.89 & 775.88 & -1167.56 & 648.80 & $5.15 \times 10^{-3}$ \\
Form B & & & & & & \\
268.15 & -20.13 & 205.25 & -772.52 & 1297.59 & -803.01 & $5.14 \times 10^{-3}$ \\
273.15 & -10.78 & 111.46 & -419.60 & 714.80 & -444.44 & $3.83 \times 10^{-3}$ \\
278.15 & 12.13 & -133.23 & 543.43 & -933.40 & 593.65 & 0.15 \\
283.15 & -20.09 & 193.32 & -676.07 & 1065.87 & -619.34 & $1.29 \times 10^{-3}$ \\
288.15 & 53.46 & -550.38 & 2113.54 & -3523.38 & 2175.54 & 0.46 \\
293.15 & 10.07 & -138.44 & 669.97 & -1302.14 & 909.16 & 0.46 \\
298.15 & 17.10 & -210.49 & 948.41 & -1771.84 & 1201.58 & 0.88 \\
303.15 & -1.99 & -33.95 & 349.46 & -879.34 & 708.39 & 0.66 \\
308.15 & 12.11 & -181.10 & 921.67 & -1851.30 & 1318.01 & 0.43 \\
\hline
\end{tabular}

Table 5. Parameters of CNIBS/R-K model for MTBE + toluene system.

\begin{tabular}{ccccccc}
\hline \multicolumn{1}{c}{$\boldsymbol{T} \mathbf{K}$} & $A_{\mathbf{0}}$ & $A_{\mathbf{1}}$ & $A_{\mathbf{2}}$ & $A_{\mathbf{3}}$ & $A_{\mathbf{4}}$ & $A R \boldsymbol{D}^{\mathbf{c}}$ \\
\hline Form A & & & & & & \\
268.15 & 2.93 & -14.50 & 31.95 & -25.98 & 7.38 & $3.33 \times 10^{-5}$ \\
273.15 & -2.85 & 24.15 & -62.23 & 76.30 & -34.29 & $1.67 \times 10^{-4}$ \\
278.15 & -5.23 & 40.73 & -103.47 & 122.26 & -53.62 & $4.93 \times 10^{-4}$ \\
283.15 & 13.09 & -95.73 & 270.85 & -323.18 & 140.77 & $1.73 \times 10^{-3}$ \\
288.15 & 0.51 & -7.34 & 44.02 & -68.49 & 35.06 & $1.30 \times 10^{-4}$ \\
293.15 & 14.54 & -111.81 & 331.94 & -413.21 & 186.39 & $2.04 \times 10^{-3}$ \\
298.15 & 36.57 & -272.47 & 763.73 & -917.64 & 402.86 & 0.03 \\
303.15 & 17.44 & -130.78 & 378.15 & -458.88 & 201.78 & $3.52 \times 10^{-3}$ \\
308.15 & 14.07 & -107.14 & 318.83 & -393.48 & 175.10 & $6.76 \times 10^{-3}$ \\
Form B & & & & & & \\
268.15 & 7.40 & -53.96 & 155.74 & -186.41 & 80.93 & $2.03 \times 10^{-3}$ \\
273.15 & 5.30 & -36.30 & 107.39 & -129.93 & 56.98 & $1.16 \times 10^{-3}$ \\
278.15 & -1.11 & 9.07 & -7.47 & -3.26 & 5.59 & $1.57 \times 10^{-6}$ \\
283.15 & -6.73 & 52.11 & -125.01 & 136.72 & -55.91 & $1.22 \times 10^{-4}$ \\
288.15 & -8.90 & 63.65 & -142.97 & 144.93 & -54.73 & $1.45 \times 10^{-3}$ \\
293.15 & -29.22 & 214.75 & -553.63 & 631.87 & -267.26 & 0.02 \\
298.15 & -18.94 & 144.72 & -375.83 & 435.24 & -187.22 & $2.16 \times 10^{-3}$ \\
303.15 & -7.52 & 59.50 & -139.44 & 150.07 & -60.82 & $1.45 \times 10^{-4}$ \\
308.15 & 0.23 & 0.16 & 30.20 & -60.21 & 34.51 & $9.61 \times 10^{-3}$ \\
\hline
\end{tabular}

Table 6. Parameters of modified Jouyban-Acree model for ethyl acetate + toluene system.

\begin{tabular}{ccc}
\hline Parameters & Form A & Form B \\
\hline$B_{0}$ & -54.84 & 78.01 \\
$B_{1}$ & -9575.17 & 1486.82 \\
$B_{2}$ & 482.53 & -525.11 \\
$B_{3}$ & -254.27 & 123.06 \\
$B_{4}$ & 27916.88 & 1322.24 \\
$B_{5}$ & $-71,896.69$ & 8370.77 \\
$B_{6}$ & $150,328.07$ & $-93,564.23$ \\
$B_{7}$ & $-108,692.03$ & $102,694.79$ \\
$B_{8}$ & 36.72 & -14.50 \\
$A R D \%$ & 2.96 & 4.06 \\
\hline
\end{tabular}


Table 7. Parameters of modified Jouyban-Acree model for MTBE + toluene system.

\begin{tabular}{ccc}
\hline Parameters & Form A & Form B \\
\hline$B_{0}$ & -9.03 & -32.63 \\
$B_{1}$ & -1580.68 & -7699.82 \\
$B_{2}$ & 107.52 & 292.16 \\
$B_{3}$ & -69.37 & -142.54 \\
$B_{4}$ & -8506.99 & 21944.77 \\
$B_{5}$ & 34761.70 & -37826.14 \\
$B_{6}$ & $-44,739.66$ & 39619.22 \\
$B_{7}$ & 20376.34 & -15596.72 \\
$B_{8}$ & 11.05 & 21.83 \\
$A R D \%$ & 3.51 & 1.82 \\
\hline
\end{tabular}

\section{Conclusions}

In this paper, the solubility data of sofosbuvir of forms $\mathbf{A}$ and $\mathbf{B}$ in ethyl acetate + toluene and $\mathrm{MTBE}+$ toluene binary solvent systems were measured at atmosphere pressure with $T=268.15-308.15$ $\mathrm{K}$ by a gravimetric method. Three models were adopted to correlate the experimental solubility data and all of them manifested satisfactory consistency, especially for CNIBS/R-K, with a higher accuracy. It was found that the solubility of sofosbuvir increases with temperature and the mole fraction of ethyl acetate or MTBE. Solubility of form B was higher than that of form A under all of the experimental conditions, which means form $\mathbf{A}$ was more stable than form $\mathbf{B}$ in the measurement temperature range. A stability test was conducted as well, finding that the two polymorphs show good solid-state stability under high temperature, high humidity, and strong light exposure conditions. All of the experimental data may provide valuable guidance for the crystallization and purification process of sofosbuvir.

Supplementary Materials: The following are available online at http://www.mdpi.com/2073-4352/10/3/209/s1, Figures S1-S6: PXRD patterns of stability tests for sofosbuvir of form A and form B, Table S1: Main data of peaks in PXRD patterns of sofosbuvir of form A and form B, Tables S2-S5: Experimental $\left(x_{A}\right)$ and calculated $\left(x_{A}{ }^{\text {cal }}\right)$ solubility data of form A and form B in binary solvents.

Author Contributions: Investigation, W.-J.J. and E.-F.W.; writing-original draft preparation, W.-J.J. and E.-F.W.; writing-review and editing, M.-H.Q. All authors have read and agreed to the published version of the manuscript.

Funding: This research received no external funding.

Acknowledgments: The authors would like to thank Zhejiang Ausun Pharmaceutical Co., Ltd., China for supplying sofosbuvir raw material.

Conflicts of Interest: The authors declare no competing financial interest.

\section{References}

1. Kattakuzhy, S.; Levy, R.; Kottilil, S. Sofosbuvir for treatment of chronic hepatitis C. Hepatol. Int. 2015, 9, 161-173. [CrossRef] [PubMed]

2. Keating, G.M.; Vaidya, A. Sofosbuvir: First global approval. Drugs 2014, 74, 273-282. [CrossRef]

3. Qi, M.-H.; Hong, M.-H.; Liu, Y.; Wang, E.-F.; Ren, F.-Z.; Ren, G.-B. Estimating Thermodynamic Stability Relationship of Polymorphs of Sofosbuvir. Cryst. Growth Des. 2015, 15, 5062-5067. [CrossRef]

4. Qiu, J.; Huang, H.; He, H.; Liu, H.; Hu, S.; Han, J.; Yi, D.; An, M.; Wang, P. Solubility Behavior and Data Modeling of L-Proline in Different Neat and Binary Solvent Systems. J. Chem. Eng. Data 2019, 64, 5920-5928. [CrossRef]

5. Liu, F.; Qu, H.; Wan, X.; Han, D.; Li, W.; Wu, S. Solubility and Data Correlation of $\beta$-Arbutin in Different Monosolvents from 283.15 to 323.15 K. J. Chem. Eng. Data 2019, 64, 5688-5697. [CrossRef]

6. Han, Z.; Hao, H.; Wu, H.; Liu, Q.; Zong, S.; Huang, X. Solubility and thermodynamic properties of dirithromycin form A and form B in pure solvents and binary solvent mixture. J. Chem. Thermodyn. 2019, 132, 240-249. [CrossRef]

7. Apelblat, A.; Manzurola, E. Solubility of oxalic, malonic, succinic, adipic, maleic, malic, citric, and tartaric acids in water from 278.15 to 338.15 K. J. Chem. Thermodyn. 1987, 19, 317-320. [CrossRef] 
8. Apelblat, A.; Manzurola, E.J. Solubilities of o-acetylsalicylic, 4-aminosalicylic, 3,5-dinitrosalicylic, and $p$-toluic acid, and magnesium-DL-aspartate in water from $\mathrm{T}=$ (278 to 348) K. J. Chem. Thermodyn. 1999, 31, 85-91. [CrossRef]

9. Yang, Z.; Shao, D.; Zhou, G. Solubility Measurement and Thermodynamic Model Correlation of Sancycline in 12 Pure Solvents. J. Chem. Eng. Data 2019, 64, 5665-5670. [CrossRef]

10. Liu, Y.; Gao, H.; Ren, F.; Ren, G. Solubility of Agomelatine Crystal Form I and Form II in Pure Solvents and (Isopropanol + Water) Mixtures. J. Chem. Eng. Data 2015, 60, 3347-3352. [CrossRef]

11. Liu, Y.; Zhao, Z.-P.; Cui, J.; Ren, G. Solubility of Amorphous Clopidogrel Hydrogen Sulfate in Different Pure Solvents. J. Chem. Eng. Data 2015, 60, 2442-2446. [CrossRef]

12. Acree, W.E., Jr.; McCargar, J.W.; Zvaigzne, A.I. Mathematical representation of thermodynamic properties. carbazole solubilities in binary alkane + dibutyl ether and alkane + tetrahydropyran solvent mixtures. Phys. Chem. Liq. 1991, 23, 27-35. [CrossRef]

13. Mohammad, B.J.; Jouyban, A. Models for calculating solubility in binary solvent systems. Int. J. Pharm 1996, 140, 237-246.

14. Barzegar-Jalali, M.; Jouyban-Gharamaleki, A. A General Model from Theoretical Cosolvency Models. Int. J. Pharm. 1997, 152, 247-250.

15. Wei, T.; Wang, C.; Du, S.; Wu, S.; Li, J.; Gong, J. Measurement and correlation of the solubility of penicillin V potassium in ethanol + water and 1-butyl alcohol + water systems. J. Chem. Eng. Data 2015, 60, 112-117. [CrossRef]

16. Acree, W.E., Jr. Mathematical representation of thermodynamic properties. Part II. Derivation of the combined nearly ideal binary solvent (NIBS)/Redlich-Kister mathematical representation from a two-body and three-body interactional mixing model. Thermochim. Acta 1992, 198, 71-79. [CrossRef]

17. Ma, H.; Qu, Y.; Zhou, Z.; Wang, S.; Li, L. Solubility of thiotriazinone in binary solvent mixtures of water + methanol and water + ethanol from (283 to 330) K. J. Chem. Eng. Data 2012, 57, 2121-2127. [CrossRef]

18. Xu, R.; Han, T.; Shen, L.; Zhao, J.; Lu, X. Solubility Determination and Modeling for Artesunate in Binary Solvent Mixtures of Methanol, Ethanol, Isopropanol, and Propylene Glycol + Water. J. Chem. Eng. Data 2019, 64, 755-762. [CrossRef]

19. Zhan, N.; Zhang, Y.; Wang, X. Solubility of N-tert-Butylbenzothiazole-2-sulfenamide in Several Pure and Binary Solvents. J. Chem. Eng. Data 2019, 64, 1051-1062. [CrossRef]

(C) 2020 by the authors. Licensee MDPI, Basel, Switzerland. This article is an open access article distributed under the terms and conditions of the Creative Commons Attribution (CC BY) license (http://creativecommons.org/licenses/by/4.0/). 